\title{
RESENHA: Uma Importante Contribuição para o Processo Grupal na Abordagem da Teoria Histórico-Cultural
}

\author{
Andaló, C. S. A. (2006). Mediação grupal: Uma leitura histórico-cultural. \\ São Paulo, SP: Ágora. \\ Marcelo Dalla Vecchia \\ Universidade Federal do Mato Grosso do Sul, Paranaíba, Brasil
}

O mercado editorial brasileiro tem se demonstrado pouco generoso no tocante à disponibilidade de publicações que permitam introduzir a questão dos grupos como preocupação da Psicologia Social, no enfoque do materialismo histórico e dialético. Aos mais incautos, este enfoque, num primeiro momento, certamente causará estranheza: como o materialismo histórico e dialético colocará o problema dos pequenos grupos? Onde situar a questão dos grupos neste sistema de pensamento, seja de uma perspectiva mais "economicista" (que vê a história como o problema do desenvolvimento contraditório das bases produtivas - relação entre forças de produção e relações sociais de produção), ou mais "voluntarista" (no qual a história é o problema do desenvolvimento contraditório das relações entre classes sociais em antagonismo)?

A indisponibilidade de publicações desta natureza exige de quem estuda, pesquisa ou intervém, a partir deste recorte, proceder a uma "coletânea pessoal" de capítulos de livros e artigos publicados de forma esparsa. Com exceção dos campos da psicoterapia grupal (nas abordagens humanista, fenomenológica e psicanalítica) e os famosos manuais ou coletâneas de técnicas pedagógicas, de vivência e sensibilização em grupo, pode-se afirmar o ineditismo do que a autora propõe ser uma "leitura histórico-cultural" do processo grupal. Sua inequívoca e explícita relação com o materialismo histórico e dialético brinda nossa afirmação.

Notamos que uma operação típica do zeitgeist pósmoderno tem sido desconsiderar mediações e determinantes histórico-estruturais fundamentais para a apreensão da ação grupal e seu significado como processo grupal, implicando na negação de uma teoria de referência ou, mutatis mutandis, na utilização de uma miscelânea de referenciais teóricos que apresentam, via de regra, pouca coerência teórica e epistemológica interna.

A autora, ao contrário, ao investir na clara delimitação das categorias e noções teóricas dos autores a partir dos quais fundamenta suas reflexões, coerentemente com seu sistema de referência, o faz apontando com lucidez os limites e possibilidades, filosóficas e epistemológicas, de tais contribuições. Ao remeter a necessidade de desenvolvimento de uma compreensão do processo grupal assentada sob as bases do materialismo histórico e dialético, resgata de Heller (1972) a noção de grupo como agência que opera uma "função mediadora entre a particularidade e a totalidade social" (Andaló, 2006, p. 33). Com clara ênfase na questão de método sustenta, assim, as categorias de totalidade e contradição como essenciais para compreender a natureza da atividade mediadora do grupo, bem como insere esta atividade na dialética singular-particular-universal.

Como outro elemento para reafirmar a importância da publicação, a autora engrossa o coro daqueles que vêm com reserva a proliferação da utilização acrítica do grupo, seja como objeto de estudo ou como recurso para a atividade profissional. Carmen Andaló denuncia o maniqueísmo ao se dar ênfase excessiva aos aspectos mais propriamente funcionais (harmonia, coesão, liderança) e/ou considerar uma suposta imanência terapêutica do "psicogrupo", a despeito do caráter conflitivo e contraditório de toda ação grupal, como indica MartínBaró (1989).

Com a utilização de uma linguagem clara, direta e pouco rebuscada, tornando a publicação acessível a uma ampla variação do público universitário e de profissionais que se preocupam com processos grupais, a autora evidencia como a "leitura histórico-cultural" possibilita superar certa microssocialização que têm acompanhado o desafio da produção de conhecimento no campo.

Fato interessante é que o livro tem a autoria de uma professora e psicóloga com sua formação pautada no psicodrama moreniano - abordagem teóricometodológica dos grupos que também conta com boa disponibilidade de publicações, verificável em qualquer rápida consulta às grandes livrarias. $\mathrm{O}$ eixo central em torno do qual a autora constrói sua argumentação, revelando a importância e especificidade desta publicação, consiste na constatação de que:

\footnotetext{
Moreno não conseguiu romper seus vínculos com a sociologia clássica e acabou adotando modelos biológicos e físicos (átomo social, estrutura, rede sociométrica etc.) para descrever os dados [ $d a$ interação grupal], numa perspectiva reducionista e associacionista típica do positivismo, como fazia Durkheim. (Andaló, 2006, p. 23).
} 
Logo na "Apresentação" da lavra de Dalmiro Manuel Bustos, fica a indicação de que a publicação revelará seu caráter heterodoxo e não-dogmático. Com efeito, a autora, no decorrer de seu livro, sustenta um diálogo entre noções teóricas do psicodrama e as categorias do materialismo histórico e dialético, sem subsumir um ao outro. Enfrenta, corajosamente e com sucesso, os riscos do acoplamento de uma farta discussão a respeito do psicodrama como estratégia e referencial conceitual para o trabalho com os grupos, por um lado, e a "leitura histórico-cultural", de outro, enriquecendo ambos.

Com relação aos seus autores de referência, Carmen Andaló ilustra Agnes Heller e Antonio Gramsci como "autores da perspectiva histórico-cultural" (Andaló, 2006, p. 13). Ainda que ela não tenha lidado diretamente com tais questões, o capítulo "O processo grupal", de Sílvia Lane (1984) - um verdadeiro marco para a perspectiva reivindicada pela autora na questão do grupo como processo histórico - por apresentar uma formulação teórica a partir de categorias tais quais alienação/consciência, ideologia e consciência individual/grupal/social, poderia oferecer aportes teóricos que enriqueceriam as reflexões de Carmen Andaló. O mesmo pode ser dito com relação a Martín-Baró (1989) e as categorias de atividade, poder e identidade grupal, bem como a afetividade como fenômeno no processo grupal (Martins, 2003).

Finalmente, ainda que sob a égide do materialismo mecanicista apregoado pela burocracia soviética, as contribuições do psicólogo soviético Petrovski $(1984,1986)$ também enriqueceriam a leitura crítica de Carmen Andaló a respeito de Kurt Lewin e a "dinâmica de grupos". Arthur Vladimirovitch Petrovski, pouco conhecido em nosso meio, traz uma sistematização de pesquisas experimentais realizadas no contexto da psicologia soviética nos anos 1970 e 1980, bem como suas principais conclusões. Também em relação a este autor, o mercado editorial brasileiro não é generoso: estas duas publicações são estrangeiras (uma delas, cubana e a outra, argentina), não sendo disponíveis traduções em português.

O ponto forte do livro fica, de fato, centrado nos dois capítulos: "Afinal, o que é o grupo?" e "O papel do coordenador de grupos". Destacando-se pela clareza de exposição, o primeiro é uma primorosa introdução ao processo grupal como problema psicossocial: desde a origem da palavra "grupo", passando ao grupo como problema sociológico e às concepções de grupo presentes nos seguintes autores da Psicologia: Kurt Lewin, Carl Rogers, Jean-Paul Sartre, Enrique Pichón-Rivière e Jacob Levy Moreno. O segundo traz as reflexões da autora em relação ao problema da coordenação de grupos indicando, desde o início, que: é importante, porém, esclarecer que tal papel [o de coordenador] se encontra atrelado à própria concepção de grupo dos profissionais que o exercem, ou seja, a qualquer caminho metodológico utilizado na investigação dos processos grupais, subjaz uma concepção de mundo e de homem nem sempre explicitada. (Andaló, 2006, p. 71).

Destacando esta questão desde os estudos de liderança realizados por Kurt Lewin, passando pela centralização na pessoa do coordenador proposta por algumas das concepções psicanalíticas de grupo e chegando à concepção da coordenação de processos grupais como ação diretiva proposta por Jacob Levy Moreno, a autora conclui este capítulo refletindo sobre a oposição entre a postura de facilitador com a de mediador na coordenação de processos grupais, argumentando em favor desta segunda como aquela que permite "resgatar seus participantes como sujeitos históricos e, consequentemente, autores de sua própria história individual e coletiva" (Andaló, 2006, p. 88).

O livro é concluído com um capítulo que reflete sobre "O protagonista como categoria conceitual" e um Apêndice, no qual a autora explicita as implicações de seu entendimento da "leitura histórico-cultural" em sua atividade como coordenadora de grupos e professora universitária.

Nos últimos anos a produção de trabalhos sobre o processo grupal fundamentado no materialismo histórico e dialético vêm tratando tanto da análise do desenvolvimento de atividades grupais, como em Lane e Freitas (1997), Zanella, Lessa e Da Ros (2002) e Zanella e Pereira (2001), quanto trabalhos que investem na revisão e produção teórica (conceitual e epistemológica) do processo grupal, também levando em conta o desenvolvimento de atividades grupais concretas, como em Martins (2002, 2003).

O livro de Carmen Andaló certamente enriquece a produção no campo, apontando o fato de que não há como se negar uma perspectiva política subjacente à própria concepção de grupo, por exemplo, se levarmos em conta que "o homem é um ser de natureza social, que tudo o que tem de humano nele provém da sua vida em sociedade, no seio da cultura criada pela humanidade" (Leontiev, 2004, p. 279 - grifos no original). Parece-nos uma importante contribuição no sentido de questionar a flagrante dissociação entre o caráter técnico e o caráter ético-político do trabalho com processos grupais que, através de uma utilização predominantemente tecnicista, tem marcado o trabalho profissional (não só do psicólogo), bem como as pesquisas no campo, com raras (e notáveis) exceções. 


\section{Referências}

Andaló, C. S. A. (2006). Mediação grupal: Uma leitura histórico-cultural. São Paulo, SP: Ágora.

Heller, A. (1972) O cotidiano e a história. Rio de Janeiro, RJ: Paz e Terra.

Lane, S. T. M. (1984). O processo grupal. In S. T. M. Lane \& W. Codo (Eds.), Psicologia Social: O homem em movimento. São Paulo, SP: Brasiliense.

Lane, S. T. M., \& Freitas, M. F. Q. (1997). Processo grupal na perspectiva de Ignácio Martín-Baró: Reflexões acerca de seis contextos concretos. Revista Interamericana de Psicologia, 31(2), 293-308.

Leontiev, A. N. (2004). O desenvolvimento do psiquismo. São Paulo, SP: Centauro.

Martín-Baró, I. (1989). Sistema, grupo y poder. Psicologia Social desde Centroamérica II. San Salvador, El Salvador: Universidad Centroamericana José Simeón Cañas.

Martins, S. T. F. (2002). Educação científica e atividade grupal na perspectiva sócio-histórica. Ciência \& Educação, 8(2), 227-235.

Martins, S. T. F. (2003). Processo grupal e a questão do poder em Martín-Baró. Psicologia \& Sociedade, 15(1), 201-217.

Petrovski, A. V. (1984). Personalidad, Actividad y Colectividad. Buenos Aires, Argentina: Cartago.

Petrovski, A. V. (1986). Teoria psicologica del colectivo. La Habana, Cuba: Editorial de Ciencias Sociales.

Zanella, A. V., Lessa, C. T., \& Da Ros, S. Z. (2002). Contextos grupais e sujeitos em relação: Contribuições às reflexões sobre grupos sociais. Psicologia: Reflexão e Crítica, 15(1), 211218.

Zanella, A. V., \& Pereira, R. S. (2001). Constituir-se enquanto grupo: A ação de sujeitos na produção do coletivo. Estudos de Psicologia (Natal), 6(1), 105-114.

Marcelo Dalla Vecchia é professor assistente da área de Psicologia Social na Universidade Federal de Mato

Grosso do Sul (UFMS), Campus de Paranaíba. Mestre em Saúde Coletiva pelo Programa de Pós-Graduação em Saúde Coletiva da Faculdade de Medicina de Botucatu pela Universidade Estadual Paulista (Unesp) e membro do Núcleo de Estudos e Pesquisas em Psicologia Social e

Educação: Contribuições do Marxismo (NEPPEM), do Programa de Pós-Graduação em Educação para a Ciência da Faculdade de Ciências/Unesp, Campus de Bauru.

mdvecchia@yahoo.com.br

\section{Resenha: Uma Importante Contribuição para o Processo Grupal na Abordagem da Teoria Histórico-Cultural}

Marcelo Dalla Vecchia

Recebido: 16/06/2007

$1^{a}$ revisão: 04/09/2007

Aceite final: 18/09/2007 